\title{
INCREASED INCIDENCE OF CYTOGENETIC ABNORMALITIES IN CHORIONIC VILLUS SAMPLES FROM PREGNANCIES ESTABLISHED BY IN VITRO FERTILIZATION AND EMBRYO TRANSFER (IVF-ET)
}

\author{
P. A. IN'T VELD, D. VAN OPSTAL, C. VAN DEN BERG, M. VAN OOIJEN, H. BRANDENBURG*, L. PIJPERS*‡, \\ M. G. J. JAHODA*, TH. STIJNEN † AND F. J. LOS \\ Departments of Clinical Genetics, *Obstetrics and Gynaecology and $\dagger$ Epidemiology and Biostatistics, \\ University Hospital Dijkzigt and Erasmus University, Rotterdam; $\ddagger$ Merwede Hospital, Dordrecht, \\ The Netherlands
}

Received 9 January 1995

Revised 23 May 1995

Accepted 18 June 1995

\section{SUMMARY}

We studied 201 pregnancies that were established by in vitro fertilization and embryo transfer (IVF-ET) and compared the frequency of cytogenetic abnormalities with that found in a large control population matched for indication group (advanced maternal age) and time of sampling. A total of 252 IVF-ET fetuses were cytogenetically analysed by either chorionic villus sampling (CVS; $n=80)$ or amniocentesis $(n=172)$. Eleven chromosome abnormalities were found in the CVS group (13.8 per cent); among them, a 45,X/46,X, $\operatorname{dic}(\mathrm{Y})(\mathrm{q} 11) / 46, \mathrm{X}, \operatorname{del}(\mathrm{Y})(\mathrm{q} 11)$ mosaic that was found in an IVF pregnancy established by intracytoplasmic sperm injection (ICSI), four cases of trisomy 21 , and three cases of trisomy 7 confined to the placenta. The results indicate a statistically significant threeto five-fold increase in both confined placental abnormalities $(P<0.008)$ and true fetal chromosome anomalies $(P<0.04)$. In the amniocentesis group, identical rates $(1.7$ per cent $)$ of chromosome abnormalities were found in the IVF-ET and control groups. It is concluded that late first trimester, but not early second trimester, IVF-ET pregnancies are characterized by an increased frequency of cytogenetic abnormalities found at prenatal diagnosis.

KEY WORDS: chorionic villi; amniocentesis; mosaicism; IVF-ET; ICSI

\section{INTRODUCTION}

The frequency of cytogenetic abnormalities in fetuses and neonates from pregnancies established by in vitro fertilization and embryo transfer (IVFET) has been the subject of a number of reports documenting birth defects in this population (AIHW, 1993; Rizk et al., 1991; Testart et al., 1992). The frequency of unbalanced chromosome aberrations was found to be comparable to that

Addressee for correspondence: Peter A. In't Veld, $\mathrm{PhD}$, Department of Clinical Genetics, Room E2471, Erasmus University, P.O. Box 1738, NL-3000 DR Rotterdam, The Netherlands. found in the general population and an IVF origin of pregnancy is generally not considered to be sufficient indication for invasive prenatal diagnosis. However, IVF pregnancies are characterized by a high frequency of spontaneous abortions between 6 and 20 weeks of gestation (AIHW, 1993), possibly indicating an increased frequency of cytogenetic abnormalities in the early IVF pregnancy, while very few studies are available that document prenatal findings in IVF populations (Würfel et al., 1992). We therefore performed a retrospective study to establish the incidence of cytogenetic abnormalities in IVF pregnancies of women referred for prenatal diagnosis because of advanced maternal age. 


\section{MATERIALS AND METHODS}

Between January 1990 and August 1994, a total of 201 women whose pregnancies were established by in vitro fertilization and embryo transfer (IVFET) at various centres in The Netherlands and Belgium were referred to our hospital for prenatal diagnosis because of advanced maternal age $(\geqslant 36$ years at 18 weeks of pregnancy). One pregnancy was established by intracytoplasmic sperm injection (ICSI) (Lanzendorf et al., 1988; Palermo et al., 1992) because of azoospermia; all the others were established by standard IVF procedures. The maternal age indication for prenatal diagnosis in the case of a donor oocyte was based on both the patient's and the donor's age. After appropriate counselling, 62 women opted for transabdominal chorionic villus sampling (TA-CVS) and 139 women opted for amniocentesis.

TA-CVS was performed at 11-14 weeks of gestation and $5-20 \mathrm{mg}$ of villi was obtained under ultrasound guidance (Jahoda et al., 1990). Villi were incubated overnight using fluorodeoxyuridine (FdU) synchronization (Gibas et al., 1987). A total of 80 karyotypes were obtained from 46 single, 14 twin, and 2 triplet pregnancies.

Amniocentesis was performed at week 16-18 of gestation and $20 \mathrm{ml}$ of amniotic fluid was aspirated under ultrasound guidance. Amniocytes were cultured in Chang medium on glass coverslips; in situ preparations were karyotyped after trypsinGiemsa staining. A total of 172 karyotypes were obtained from 110 single, 25 twin, and 4 triplet pregnancies.

The frequency of cytogenetic abnormalities in the IVF-ET population was compared with that in the control population consisting of pregnancies that were not established by IVF-ET and referred for prenatal diagnosis to our centre during the same period because of advanced maternal age. Control populations consisted of 4406 CVS and 3251 amniocenteses. Statistical analysis, in which the frequency of cytogenetic abnormalities in the various groups was compared for each age category, was carried out by the exact MantelHaenszel procedure. Odds ratios were corrected for both maternal age and gestational age in the CVS group.

Fluorescent in situ hybridization (FISH) was performed on cultured amniocytes as described previously (Van Opstal et al., 1993). The following probes were applied: pDP105 (DYZ4) (Gal et al., 1987) hybridizing to Yp; pDP97 (DYZ3) (Wolfe et al., 1985) hybridizing to the $\mathrm{Y}$ centromere; $\mathrm{p} 49 \mathrm{f}$ (DY31) (Ngo et al., 1986) hybridizing to Yq11; and AmprobeRPN1305X (Lau, 1985) hybridizing to the heterochromatic part of Yq.

\section{RESULTS}

In chorionic villus biopsies from IVF-ET pregnancies, a total of 11 cytogenetic abnormalities were found (excluding single cell aneuploidy and familial structural abnormalities), consisting of six fetal abnormalities and five confined placental mosaics (Table I). The fetal abnormalities comprised a case of XYY and four cases of aneuploidy for chromosome 21 ; all four cases were accompanied by echographic abnormalities (hydrops fetalis and/or hygroma colli) that were detected at the time of biopsy at 11-14 weeks of gestation. Two of these cases involved twin pregnancies which were selectively terminated. No material for confirmation of the fetal karyotype could be obtained from the selectively terminated cases. The single pregnancy that was established by intracytoplasmic sperm injection (ICSI) presented with a mosaic $45, X / 46, X, \operatorname{dic}(Y)(q 11) / 46, X, \operatorname{del}(Y)(q 11)$ which was confirmed in amniotic fluid cells and fetal fibroblasts. Blood samples from both parents yielded normal karyotypes in 100 metaphases. The two derivative $\mathrm{Y}$ chromosomes (Fig. 1A) were characterized by FISH: both derivatives were negative with AmprobeRPN1305X and p49f indicating the absence of the heterochromatic region and substantial loss of euchromatin; probes pDP105 and pDP97 both showed two signals on the dic(Y)(q11) (Figs 1B and 1C) and one signal on the $\operatorname{del}(\mathrm{Y})(\mathrm{q} 11)$. The pregnancy was terminated at the parents' request; obduction showed a male fetus without apparent congenital malformations.

Comparison of the frequency of fetal cytogenetic abnormalities in IVF pregnancies sampled by CVS $(6 / 80 ; 7.5$ per cent) with that in a control population $(75 / 4406 ; 1.7$ per cent) indicated a significant increase in the frequency of cytogenetic abnormalities in the IVF group $(P<0.04$; odds ratio corrected for both maternal and gestational age 3.6; 95 per cent confidence interval $1 \cdot 1-9 \cdot 6$ ).

The five cases of confined placental mosaicism comprised one case in which both an additional chromosome 7 and an additional chromosome 13 were present, two cases with trisomy 7 , and two cases of sex chromosome mosaicism. In the control population a total of eight cases involving an 
Table I-Cytogenetic abnormalities in chorionic villus samples from IVF-ET patients referred for advanced maternal age

\begin{tabular}{|c|c|c|c|c|}
\hline $\begin{array}{l}\text { Case } \\
\text { No. }\end{array}$ & $\begin{array}{c}\text { Age } \\
\text { (years) }\end{array}$ & $\begin{array}{c}\text { Gestational } \\
\text { age } \\
\text { (weeks) }\end{array}$ & Karyotype & Follow-up \\
\hline
\end{tabular}

\section{Fetal abnormalities}

$\begin{array}{lll}1^{*} & 37 & 13 \\ 2^{*} & 36 & 12 \\ 3^{*} & 38 & 12 \\ 4 & 43 & 14 \\ 5 & 39 & 12 \\ 6 & 38 & 13\end{array}$

\author{
$47, X Y,+21$ \\ $47, \mathrm{XYY}$ \\ $47, \mathrm{XX},+21$ \\ $47, X Y,+21$ \\ $46, \mathrm{XX} / 47, \mathrm{XX},+21(2 / 28)$ \\ $45, \mathrm{X} / 46, \mathrm{X}, \operatorname{dic}(\mathrm{Y})(\mathrm{q} 11) / 46, \mathrm{X}, \operatorname{del}(\mathrm{Y})(\mathrm{q} 11)$ \\ $(4 / 14 / 16)$
}

Placental abnormalities

$\begin{array}{ccc}7 & 39 & 12 \\ 8^{*} & 38 & 12 \\ 9 & 37 & 11 \\ 10^{*} & 40 & 13 \\ 11 & 35 & 11\end{array}$

\author{
$45, \mathrm{X} / 46, \mathrm{XY}(12 / 22)$ \\ $46, \mathrm{XY} / 47, \mathrm{XY},+7 / 48, \mathrm{XY},+7,+13(8 / 2 / 40)$ \\ $46, \mathrm{XY} / 47, \mathrm{XY},+7(11 / 21)$ \\ $45, \mathrm{X} / 46, \mathrm{XX}(2 / 18)$ \\ $47, \mathrm{XX},+7$
}

\author{
Selective TOP; NF \\ Continued pregnancy \\ Selective TOP; NF \\ TOP; 47,XY,+21 (F) \\ TOP; $47, \mathrm{XX},+21$ (F) \\ 45,X/46,X,dic(Y)(q11)/46,X,del(Y)(q11) \\ TOP (AC; F) \\ NF; normal boy \\ 46,XY (AC) \\ $46, X Y(\mathrm{LTC} ; \mathrm{AC})$ \\ $46, \mathrm{XX}(\mathrm{AC})$ \\ $46, \mathrm{XX}(\mathrm{AC})$
}

$\mathrm{AC}=$ Amniocentesis; $\mathrm{LTC}=$ long-term villus culture; $\mathrm{F}=$ fetal skin biopsy; $\mathrm{TOP}=$ termination of pregnancy; $\mathrm{NF}=$ no cytogenetic follow-up. An asterisk denotes a twin pregnancy; a normal karyotype was found by CVS in the second fetus.

additional chromosome 7 were present. Comparison of the frequency of all placental cytogenetic abnormalities $(5 / 80 ; 6.2$ per cent) with that in a control population $(55 / 4406 ; 1.2$ per cent) indicated a significant five-fold increase of placental cytogenetic abnormalities in the IVF population sampled by CVS $(P<0.008$; odds ratio corrected for both maternal and gestational age 5.6; 95 per cent confidence interval $1 \cdot 6-15 \cdot 2$ ).

In amniotic fluid samples obtained from IVF-ET pregnancies, a total of three cytogenetic abnormalities were found (excluding pseudomosaicism and familial structural abnormalities). All three cases involved trisomy 21 (Table II). The frequency of non-familial cytogenetic abnormalities in the IVF population was $3 / 172$ ( 1.7 per cent), which is identical (odds ratio corrected for maternal age $1 \cdot 0 ; 95$ per cent confidence interval $0 \cdot 2-3 \cdot 2$ ) to the frequency in the control population of $56 / 3251$ ( 1.7 per cent).

\section{DISCUSSION}

The present study documents cytogenetic abnormalities in a population of 252 fetuses from pregnancies of women referred for prenatal diagnosis because of advanced maternal age whose pregnancy was established by in vitro fertilization and embryo transfer (IVF-ET). It compares the frequency of such abnormalities with that in a control population matched for indication group and period of sampling, and concludes that the frequency of cytogenetic abnormalities found in chorionic villi sampled at 11-14 weeks of gestation is significantly increased in the IVF-ET pregnancies. In contrast, the frequency of such abnormalities encountered after amniocentesis at 16-18 weeks of gestation was found to be similar to that in the controls.

Chromosome abnormalities found in chorionic villi can be divided into true fetal abnormalities and abnormalities confined to the placenta. A three- to four-fold higher frequency of fetal abnormalities was found in the IVF-ET population: apart from four cases of trisomy 21 and a case of $\mathrm{XYY}$, a complex chromosome mosaic 45,X/ $46, X, \operatorname{dic}(Y)(q 11) / 46, X, \operatorname{del}(Y)(q 11)$ was found in the single pregnancy that was established by intracytoplasmic sperm injection (ICSI). Combinations of $\mathrm{XO}$ and dicentric $\mathrm{Yp}$ or deleted $\mathrm{Yq}$ lines have been described previously, with patients presenting with a wide range of different phenotypes ( $\mathrm{Hsu}$, 1994). Apart from the present finding, a total of five other chromosome aberrations have been described after ICSI (Bonduelle et al., 1994). Interestingly, all the cases involve sex chromosome abnormalities, possibly indicating that the ICSI 


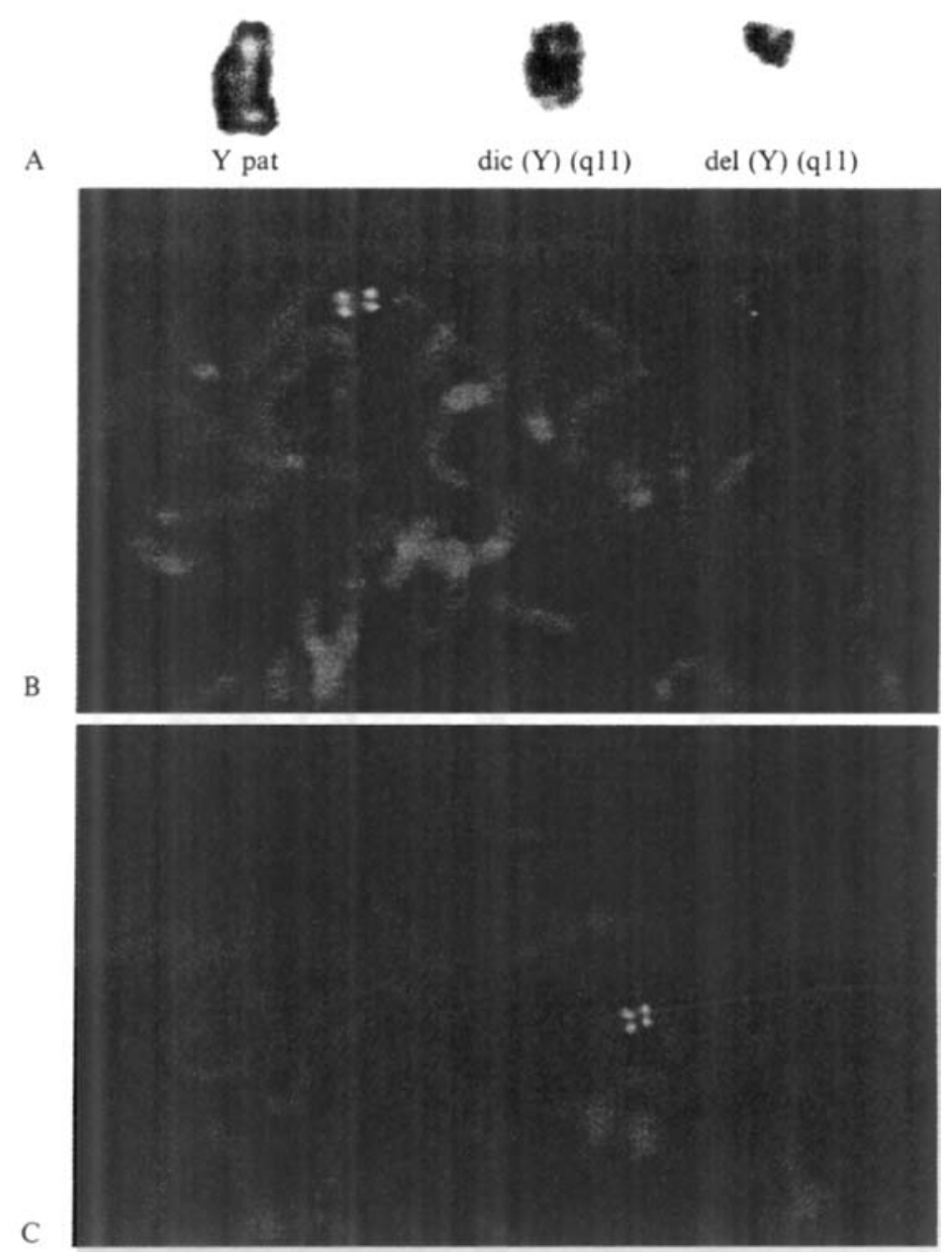

Fig. 1-(A) Paternal $Y$ chromosome (left) and fetal derivative $Y$ chromosomes (right) in a pregnancy established by intracytoplasmic sperm injection (ICSI) (GTG banding). (B) Partial metaphase with fluorescent in situ hybridization signals after hybridization with the $Y$ centromere probe pDP97 and $(C)$ the Yp probe pDP105 showing two signals on both chromatids of the $\operatorname{dic}(Y)(q 11)$

technique is associated with an increased prevalence of sex chromosomal aberrations. As ICSI bypasses sperm selection and involves the injection of an entire spermatozoon into the ooplasm, it can be speculated that the increase is either due to the ICSI technique itself or is related to the (paternal) fertility problems which have led to the choice of ICSI as fertility treatment.

The frequency of confined placental abnormalities was found to be five-fold higher in the IVF-ET population sampled by CVS. Apart from two cases with a low-grade mosaic $45, \mathrm{X}$, three cases of trisomy 7 were found; both types of aneuploidy are a relatively common finding in CVS (Sachs et al., 1990), but the frequency of trisomy 7 , either alone or in conjunction with another trisomy, was found to be 20 -fold higher in the IVF-ET group than in the controls. The finding of (mosaic) trisomy 7 in a chorionic villus biopsy has not been reported to be associated with the presence of (mosaic) trisomy 7 in the fetus, but may be associated with a higher risk of cystic fibrosis (CF) through uniparental isodisomy from a mutation carrier (Spence et al., 1988). If an increased frequency of trisomy 7 placentae is not only present in classical IVF pregnancies, but is 
Table II-Cytogenetic abnormalities in amniotic fluid samples from IVF-ET patients referred for advanced maternal age

\begin{tabular}{|c|c|c|c|c|}
\hline $\begin{array}{l}\text { Case } \\
\text { No. }\end{array}$ & $\begin{array}{c}\text { Age } \\
\text { (years) }\end{array}$ & $\begin{array}{l}\text { Gestational } \\
\text { age } \\
\text { (weeks) }\end{array}$ & Karyotype & Follow up \\
\hline $1^{*}$ & 41 & 16 & $47, \mathrm{XX},+21$ & $\begin{array}{c}47, \mathrm{XX},+21(\mathrm{FB}) \\
\text { Selective TOP }\end{array}$ \\
\hline $\begin{array}{l}2 \\
3\end{array}$ & $\begin{array}{l}40 \\
39\end{array}$ & $\begin{array}{l}18 \\
16\end{array}$ & $\begin{array}{c}47, X Y,+21 \\
46, X Y / 47, X Y,+21 \\
(3 / 28)\end{array}$ & $\begin{array}{c}\text { TOP; NF } \\
46, \mathrm{XY} / 47, \mathrm{XY},+21(\mathrm{~F}) \\
(6 / 40) ; \mathrm{TOP}\end{array}$ \\
\hline
\end{tabular}

$\mathrm{FB}=$ Fetal blood; $\mathrm{F}=$ fetal skin biopsy; $\mathrm{NF}=$ no cytogenetic follow-up; $\mathrm{TOP}=$ termination of pregnancy. An asterisk denotes a twin pregnancy; a normal karyotype was found after amniocentesis in the second fetus.

also present after intracytoplasmic sperm injection (ICSI), this finding may be important as ICSI treatment is considered the fertility treatment of choice in males with congenital bilateral absence of the vasa deferentia (Devroey et al., 1994), a condition known to be associated with (compound) heterozygosity for mutations in the $\mathrm{CF}$ gene (Anguiano et al., 1992).

In the IVF-ET group sampled by amniocentesis, the frequency of chromosome aberrations was not found to be different from that in a large control population; this contrasts with the finding in the IVF-ET group sampled by CVS in which marked differences with the controls were observed. Several factors may account for the different amniocentesis and CVS results: a high level (29 per cent) of spontaneous abortions was reported in the group of IVF pregnancies with a maternal age over 35 years (AIHW, 1993). The fetal cytogenetic abnormalities observed after CVS may thus represent pregnancies that would have aborted spontaneously before amniocentesis at 16 weeks of gestation. This possibility is supported by the observation that all four cases of trisomy 21 found in this group showed hydrops fetalis and/or hygroma colli, conditions that, if the pregnancy had not been terminated at the parents' request, might have led to a spontaneous abortion. Analysis of spontaneous abortions after IVF has documented chromosomally abnormal cases aborted between 11 and 16 weeks of gestation (Plachot, 1989). If an IVF pregnancy has an increased risk of a spontaneous abortion associated with a chromosome abnormality, it could be argued that prenatal diagnosis via amniocentesis at 16 weeks of gestation is the most suitable approach in these pregnancies (excluding the multiple gestations) as it would avoid unnecessary interventions. On the other hand, the increased risk of a confined placental abnormality argues in favour of CVS in those cases in which uniparental disomy, especially of chromosome 7, could be of importance, as it is in pregnancies at risk for cystic fibrosis.

An alternative explanation for the difference between the amniocentesis and CVS groups may be found in the vanishing twin hypothesis (Tharapel et al., 1989), in which resorption of a co-twin results in a cytogenetically mixed placenta containing cells from both the continuing pregnancy and the vanished twin. As IVF pregnancies are characterized by a high frequency of twin and triplet gestations, some of which spontaneously reduce to singleton and twin gestations, such a model may help to explain the increased frequency of placental anomalies found in CVS. However, in this model, discrepancies may be expected to occur between the sex established by CVS and that found after examination of fetal tissues; none has been found in the present series. The results of this retrospective study emphasize the continuing need for a close (cytogenetic) follow-up of pregnancies established by IVF-ET.

\section{ACKNOWLEDGEMENTS}

We thank Dr J. O. Van Hemel for reading the manuscript, A. Seinstra and N. van Koetsveld for expert technical assistance, A. Braat for generating Fig. 1, and Professor Dr H. Galjaard for his continued support. 


\section{REFERENCES}

AIHW National Perinatal Statistics Unit and Fertility Society of Australia (1993). Assisted Conception Australia and New Zealand 1991, Sydney: AIHW.

Anguiano, A., Oates, R.D., Amos, J.A., Dean, M., Gerrard, B., Stewart, C., Maher, T.A., White, M.B., Milunsky, A. (1992). Congenital bilateral absence of the vas deferens: a primarily genital form of cystic fibrosis, J. Am. Med. Assoc., 267, 1794-1797.

Bonduelle, M., Liebaers, I., Legein, J., Buysse, A., Magnus, M., Wisanto, A., Silber, S., DeVroey, P., Van Assche, E., Van Steirteghem, A. (1994). Malformation rates from IVF and/or assisted fertilization (ICSI or ICSI after MESA/TESA). Proceedings of the 4th International Workshop on Assisted Fertilization by Intracytoplasmic Injection of Epididymal and Testicular Sperm, Brussels: ESHRE.

Devroey, P., Liu, J., Nagy, Z., Tournaye, H., Silber, S.J., van Steirteghem A.C. (1994). Normal fertilization of human oocytes after testicular sperm extraction and intracytoplasmic sperm injection, Fertil. Steril., 62, 639-641.

Gal, A., Weber, B., Neri, G., Serra, A., Müller, U., Schempp, W., Page, D.C. (1987). A 45,X male with Y-specific DNA translocated onto chromosome 15, Am. J. Hum. Genet., 40, 477-488.

Gibas, L.M., Grujic, S., Barr, M.A., Jackson, L.G. (1987). A simple technique for obtaining high quality chromosome preparations from chorionic villus samples using FdU synchronization, Prenat. Diagn., 7, 323-327.

Hsu, L.Y.F. (1994). Phenotype/karyotype correlations of $\mathrm{Y}$ chromosome aneuploidy with emphasis on structural aberrations in postnatally diagnosed cases, $\mathrm{Am}$. J. Med. Genet., 53, 108-140.

Jahoda, M.G.J., Pijpers, L., Reuss, A., Brandenburg, H., Cohen-Overbeek, T.E., Los, F.J., Sachs, E.S., Wladimiroff, J.W. (1990). Transabdominal villus sampling in early second trimester: a safe sampling method for women of advanced age, Prenat. Diagn., 10, 307-311.

Lau, Y.F. (1985). Organization of the human Y-specific HaeIII $3.4 \mathrm{~Kb}$ repeat sequences and their application in clinical diagnosis. In: The $Y$ chromosome, Part A, New York: Alan R. Liss, 177-192.

Lanzendorf, S.E., Slusser, J., Maloney, M.K., Hodgen, G.D., Veeck, L.L., Rosenwaks, Z. (1988). A preclinical evaluation of pronuclear formation by microinjection of human spermatozoa into human oocytes, Fertil. Steril., 49, 835-842.
Ngo, K.Y., Vergnaud, G., Johnsson, C., Lucotte, G., Weissenbach, J. (1986). A DNA probe detecting multiple haplotypes of the human $\mathrm{Y}$ chromosome, Am. J. Hum. Genet., 38, 407-418.

Palermo, G., Joris, H., DeVroey, P., Van Steirteghem, A.C. (1992). Pregnancies after intracytoplasmic injection of single spermatozoon into an oocyte, Lancet, 340, 17-18.

Plachot, M. (1989). Chromosome analysis of spontaneous abortions after IVF. A European survey, Hum. Reprod., 4, 425-429.

Rizk, B., Doyle, P., Tan, S.L., Rainsbury, P., Brinsden, P., Edwards, R. (1991). Perinatal outcome and congenital malformations in in-vitro fertilization babies from the Bourn-Hallam group, Hum. Reprod., 6, 1259-1264.

Sachs, E.S., Jahoda, M.G.J., Los, F.J., Pijpers, L., Reuss, A., Wladimiroff, J.W. (1990). Interpretation of chromosome mosaicism and discrepancies in chorionic villi studies, Am. J. Med. Genet., 37, 268-271.

Spence, J.E., Perciaccante, R.G., Greig, G.M., Willard, H.F., Ledbetter, D.H., Hejtmancik, J.F., Pollack, M.S., O'Brien, W.E., Beaudet, A.L. (1988). Uniparental disomy as a mechanism for human genetic disease, Am. J. Hum. Genet., 42, 217-226.

Testart, J., Plachot, M., Mandelbaum, J., Salat-Baroux, J., Frydman, R., Cohen, J. (1992). World collaborative report in IVF-ET and GIFT: 1989 results, Hum. Reprod., 7, 362-369.

Tharapel, A.T., Elias, S., Shulman, L.P., Seely, L., Emerson, D.S., Simpson, J.L. (1989). Resorbed co-twin as an explanation for discrepant chorionic villus results: non-mosaic $47, \mathrm{XX},+16$ in villi (direct and culture) with normal $(46, \mathrm{XX})$ amniotic fluid and neonatal blood, Prenat. Diagn., 9, 467-472.

Van Opstal, D., Eussen, H.J., Van Hemel, J.O., Sachs, E.S. (1993). Application of fluorescent in situ hybridization for 'de novo' anomalies in prenatal diagnosis, Prenat. Diagn., 13, 825-832.

Wolfe, J., Darling, S.M., Erickson, E.S., Graig, I.W., Buckle, V.J., Riby, P.W.J., Willard, H.F., Goodfellow, P.N. (1985). Isolation and characterization of an alphoid centromeric repeat family from the human Y chromosome, J. Mol. Biol., 182, 447-485.

Würfel, W., Haas-Andela, H., Krüsmann, G., Rothenaicher, M., Hirsch, P., Kwapisz, H.K., Haas, J., Högemann, I., Fiedler, K. (1992). Prenatal diagnosis by amniocentesis in 82 pregnancies after in vitro fertilization, Eur. J. Obstet. Gynecol. Reprod. Biol., 44, $47-52$. 